\title{
Dynamic identification of historic masonry structures
}

\author{
Maria-Giovanna Masciotta, Luís F. Ramos \\ ISISE, University of Minho, Department of Civil Engineering, Guimarães, Portugal
}

\subsection{Introduction}

Dynamic identification is the characterization of the main dynamic properties of structural systems based on the analysis of their vibration responses to an input force. Such properties, referred to as modal parameters (i.e., frequencies, mode shapes, and damping ratios), define the inherent characteristics or "fingerprints" of the system and provide useful information about its state. Modal parameters are related to the physical and mechanical properties of the analyzed structure, like mass, stiffness, and energy dissipation, thereby allowing for their characterization even in the absence of viable experimental testing procedures, through the solution of an inverse problem. This relationship also implies that any structural changes a system may undergo over time will be reflected by changes in its modal properties, hence the importance of tracking the dynamic response of structures also for damage identification purposes. Circumstances show that built environment is continuously exposed to the risk of damage, whether due to exogenous or endogenous causes. If not detected in due time, such an adverse condition can compromise the structural integrity and ultimately jeopardize users' safety.

Within this context, dynamic identification plays a leading role, as it offers real-time punctual checkups of the structural fitness, driving the application of supervised vibration-based damage identification methods to spot the weakest and most vulnerable areas of a structure in due time. Furthermore, by following the evolution of modal parameters through the consecutive repetition of dynamic measurements over time, one can obtain on a systematic basis nearly real-time information about the health status of the monitored system and timely detect anomalies if the structure does not behave as expected. This continuous acquisition process and analysis of data from the structure is referred to as structural health monitoring.

Either performed in a continuous or intermittent way, dynamic testing can be considered a kind of global nondestructive health monitoring tool since it enables one to estimate the modal features by only embedding an array of sensors in the structure and recording the corresponding response processes, without resorting to any invasive technique. This aspect, which definitely represents one of the major strengths of dynamic testing, gains further importance when dealing with cultural heritage assets, where the need to respect the historical value of the constructions often limits the range of applicable techniques for the system characterization. 
Another benefit that is worthwhile to mention consists of the possibility to exploit dynamic testing for the evaluation of the system response before and after structural interventions, allowing one to control and appraise the effectiveness of the adopted remedial solutions.

All these considerations throw light on the remarkable increase that dynamic vibration testing has seen in the last decades as a preferred tool for the assessment of the global health conditions of civil and monumental structures, as well as for the development of realistic behavioral models of complex engineering systems. In detail, modal analysis has been widely implemented in aerospace, mechanical, and civil engineering applications for vibration trouble shooting, structural dynamics modification, analytical model updating, optimal dynamic design, vibration control, and vibration-based structural health monitoring (Zhang et al., 2005). Well-established methods and system identification algorithms for the extraction of the most relevant modal parameters from the measurements of the dynamic response have also been developed (Maia and Silva, 1997; Reynders, 2012). However, the transfer of input devices typically used in mechanical engineering to the civil engineering field is not always feasible, as exciting large civil structures in a controlled manner can often be impractical. Notwithstanding, the ceaseless technologic progress in transducers and analog-to-digital converters has allowed us to overcome this limitation by making operational modal analysis possible. Unlike traditional experimental modal analysis (EMA) where both excitation and structural response are measured, and modal parameters are deterministically estimated from input-output data, operational modal analysis (OMA) only requires records of the structural response to freely available natural excitation sources, such as traffic, wind, streams, and microtremors. As this type of excitation is random in nature and cannot be measured exactly, the main assumption on which OMA relies is the consideration of ambient excitation as a stationary Gaussian white noise stochastic process, viz. a broadband random signal with flat power spectrum in the frequency range of interest for the structure. In this case, with the input load being unknown, modal parameters are identified from output-only data by applying suitable stochastic modal identification techniques.

The main scope of this chapter is to provide a brief overview of both forced and ambient vibration testing procedures along with their relevant input-output and output-only modal identification techniques, focusing on their application to historic masonry buildings. As widely known, the uniqueness and complexity of ancient structures make the understanding of their behavior a true challenge. Full-scale in situ experimentation represents the only way to shed light upon the actual performance of these constructed systems and to create a thorough knowledge about built heritage. Hereafter, the results from full-scale dynamic testing of three historic masonry buildings are presented and discussed. The Qutb Minar tower in India, one of the tallest stone masonry towers in the world, is among the investigated monuments. For each of the presented case studies, the application of vibration tests and modal analysis procedures for the characterization of the system's dynamic behavior is fully described, showing how the information obtained enlightens as to 
the actual response of the structure and may be exploited for structural assessment purposes.

\subsection{Theoretical background}

\subsubsection{Testing procedures for modal identification of structural systems}

Conventional modal testing procedures are performed by exciting the structure with a known input force and capturing its response by a set of sensors deployed at selected locations along the structure, trying to operate with high enough spatial density and frequency resolution. The identification of the modal parameters is then obtained by estimating the frequency response functions (FRFs) or the impulse response functions (IRFs) from input-output data. Before performing experimental tests, it is recommended to carry out preliminary FE modal analyses to drive the selection of measurement points (number and location), time duration, and sampling rate of output signals.

The dynamic response of the structure can be measured by any kind of device able to convert physical quantities such as displacements, velocities, accelerations, strains, etc., into proportional electrical signals, ready to be processed by the data acquisition system (DAQ). Displacements and velocities transducers are all suited for this purpose, but usually equipment based on accelerometers (piezoelectric, piezoresistive, capacitive, or force balance) are preferred, because of their relatively low cost and high sensitivity at the same time (Fig. 8.1). However, the so-recorded response signals are rather low and must be amplified by conditioning units provided with both noise and antialiasing filters. Then, to be processed, the measured continuous analog signals are converted to discrete digital signals through an analog-to-digital converter (Masciotta, 2015).

Once acquired, the digital raw signals have to be preliminarily analyzed and processed. This means (1) check the data for clipping, drop-out voltage, and spikes;
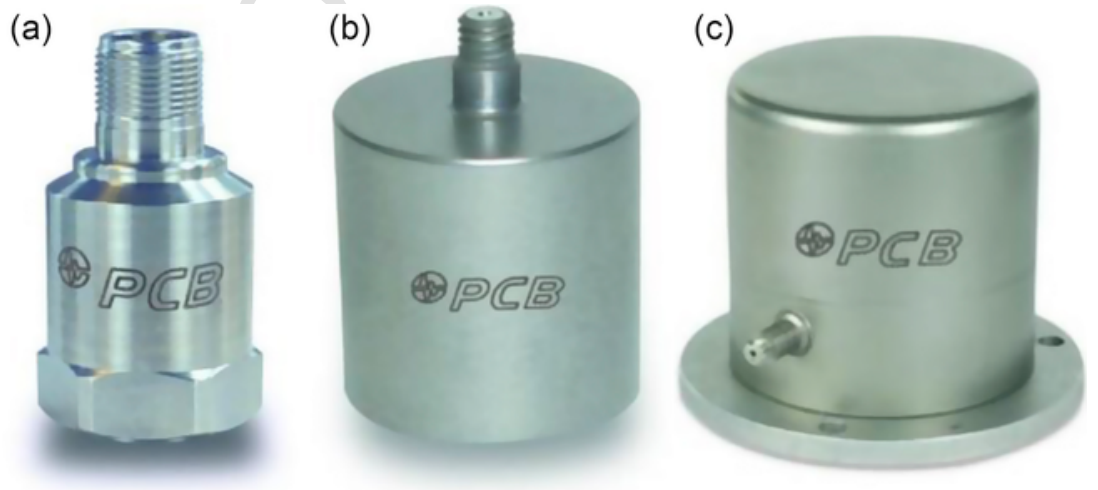

Figure 8.1 Examples of high-sensitivity piezoelectric accelerometers for vibration monitoring of civil structures (www.pbc.com): (a) Model 393B12, (b) Model 393B04, (c) Model 393C. 
(2) de-trend the signals by removing any possible trend due to a slowly varying mean value; (3) filter the signals to get rid of undesired frequency components through the application of different types of window functions in the frequency domain, i.e., high-pass, low-pass, or band-pass; (4) down-sample (decimate) the signals to reduce the number of values in the time histories and speed up the processing time for the subsequent modal identification; and (5) reduce leakage errors caused by differences between sampling time and signal period through appropriate time windowing, such as Hanning, cosine-taper, and the like (Fig. 8.2).

After preprocessing the data, it is possible to proceed with the modal identification of the structure either by frequency domain (FD) or by time domain (TD) approaches. Obviously, the use of two or more identification methods will lead to major confidence in the results.

\subsubsection{Output-only modal identification}

Modal identification methods capable of estimating the modal parameters of a structure from unknown natural ambient excitation are named output-only identification techniques, also referred to as OMA (Reynders, 2012; Peeters and De Roeck, 2001; Brincker and Kirkegaard, 2001). The main assumption on which OMA
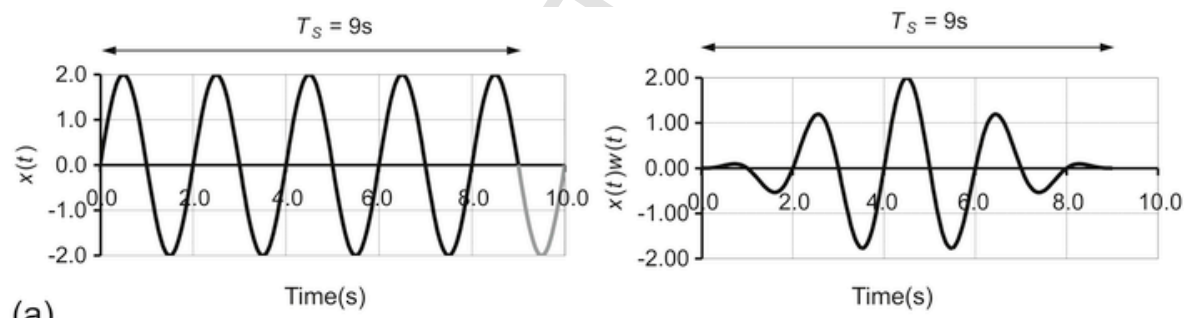

(a)
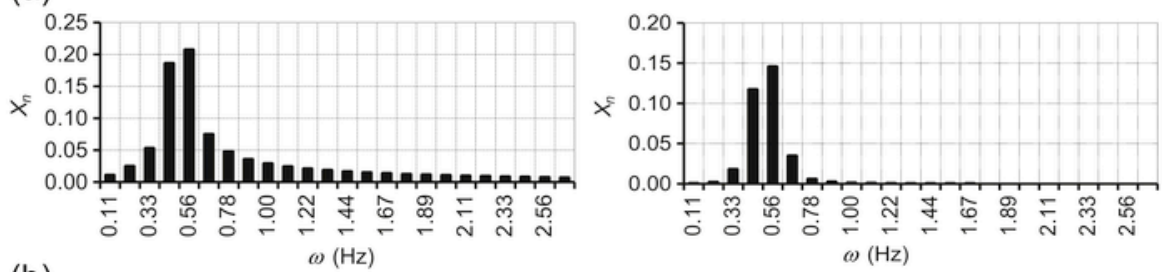

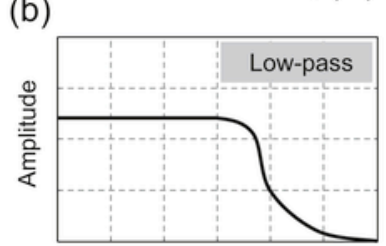

Frequency

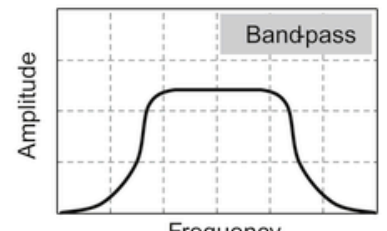

Frequency

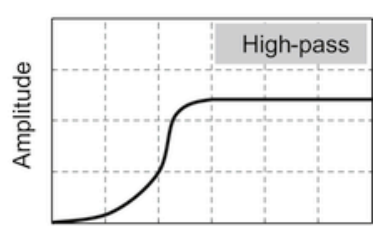

Frequency

Figure 8.2 Digital processing. (a) Hanning window application: signal before and after windowing and corresponding discrete Fourier spectra; and (b) main frequency filtering windows. 
relies is the consideration of the excitation as a stationary Gaussian white noise stochastic process. Although this does not reflect the reality, it is anyway a good approximation since the excitation can be seen as the response to a linear filter excited with white noise input.

Compared to traditional EMA, OMA results are much more attractive and reliable as a dynamic identification tool. The main benefits characterizing output-only identification techniques are (1) the possibility of measuring the response of the structure using freely available environmental excitations, such as wind, traffic, microtremors, and human walking (the more the input randomness, the better the modal results); (2) the low cost of the tests since no heavy and expensive equipment is necessary; and (3) the possibility of carrying out real in situ testing, based on true boundary conditions and on real in-operation conditions, without interrupting the normal use of the structure. Additionally, since ambient excitation provides multiples inputs, OMA is clearly based on multiple-input/multiple-output (MIMO) techniques, thus even closely spaced modes can be estimated. The only shortcoming might arise in the presence of a low level of ambient excitation, a factor that can hamper the identification of high-frequency modes.

Two main groups can be distinguished within output-only modal identification methods: nonparametric methods developed in FD and parametric methods developed in TD. The first group is based on the estimation of modal parameters from the power spectral densities of the measured output signals after the application of the FFT process. The second group is based on the identification of modal parameters by fitting the response correlation functions (obtained from FFT algorithm or random decrement method) of each measurement point to a mathematical model representative of the dynamic behavior of the structure. It is worth noting that FD methods are simpler and faster in comparison to TD methods, but they are limited by the frequency resolution of the spectral density estimates that, if low, can lead to heavily biased modal estimates.

Depending on the number of steps involved, both FD and TD methods can be further classified in two-stage or one-stage approaches. The two-stage approach estimates correlation functions (TD) or power spectral densities (FD) in the first stage, and then extracts modal parameters from these estimates. The one-stage approach directly extracts modal parameters from the discrete time histories (TD) or the Fourier transforms (FD) of the output signals.

Many dynamic identification algorithms have been developed since the 1990s, from the basic frequency domain technique, namely the peak picking (PP), to the improved frequency domain decomposition (FDD) and the more refined enhanced frequency domain decomposition (EFDD) and frequency-spatial domain decomposition techniques, from stochastic subspace identification (SSI) methods - either covariance or data-driven - to procedures that originate from traditional EMA techniques, such as Ibrahim time domain (ITD), auto regressive moving average (ARMA), complex exponential (CE), least square complex exponential (LSCE), polyreference complex exponential (PRCE), and eigensystem realization algorithm (ERA). 


\subsubsection{Input-output modal identification}

Modal identification methods based on the use of both input (excitation) and output (response) measurements to estimate the modal parameters are called input-output dynamic identification techniques and belong to the field of traditional EMA (Maia and Silva, 1997; Ewins, 2000; Cunha and Caetano, 2006). Since the 1960s, EMA has obtained substantial progress and numerous modal identification algorithms have been developed, from single-input/single-output techniques to single-input/ multi-output and MIMO techniques, either in the TD or FD. The goal of these identification methods is to extract as many modal information as possible by properly exciting the structure during the experimental testing.

As far as civil structures are concerned, forced-vibration tests can be carried out using different excitation mechanisms, such as impact hammers, drop weight systems, or shakers, which have to be adequately chosen with respect to the size of the structure to be tested. For instance, impact hammers can work satisfactorily in the case of small and medium-size structures, but in the case of large structures, a greater amount of energy is needed to excite all the relevant vibration modes, thus electro-dynamic or electro-hydraulic shakers as well as eccentric mass vibrators may be more suitable for attaining higher frequency resolution.

Input-output modal identification algorithms rely on deterministic estimates of FRFs in the FD or IRFs in the TD. Such functions describe the response of a linear time-invariant system for all frequencies. In the FD, modal identification techniques can range from simpler SDOF formulations-like PP, circle-fit and inverse method (IM) - to more sophisticated MDOF formulations, like rational fraction polynomial, complex exponential frequency domain, and polyreference frequency domain. On the other hand, in the TD, either direct methods, such as ARMA, and indirect methods - like CE, LSCE, PRCE, ITD, and ERA - can be employed. Given the limitations on the resolution of FD methods and the possible presence of leakage errors in the estimates, TD methods are usually preferred when a large frequency range or a large number of modes exist in the data (Cunha and Caetano, 2006).

Although there is a wide field of application, traditional EMA presents some drawbacks, such as the difficulty in artificially exciting large and complex structures with sufficient energy and in a controlled manner, the high cost of the equipment required for testing, and the impossibility to adequately simulate real operation conditions in a lab environment. These limitations led the civil engineering community to focus on modal identification techniques based on response measurements only, a great alternative to traditional EMA.

\subsubsection{General remarks}

Although there are outstanding advantages, output-only modal identification techniques present several shortcomings. One of the main drawbacks is the impossibility of mode shapes scaling due to lack of input information. Mass normalized mode shapes are needed in applications such as structural health 
monitoring or vibration-based damage identification, so the knowledge of the scaling factors of the mode shapes is important. To overcome this issue, some methods based on repeated testing introducing mass changes have already been proposed (at first by Parloo et al., 2001; Brincker and Andersen, 2003). Another approach recently addressed (Aenlle and Brincker, 2013) is to update a finite element model of the structure using modal parameters estimated by OMA and, if a good correlation is present, to scale the experimental mode shapes using the mass matrix of the finite element model.

The structural mode sorting is another drawback of OMA: in many practical cases, in addition to random loads, background noise and/or harmonic excitations due to rotating machinery and/or fluctuating forces are also present. Due to that, the distinction between structural modes and noise or spurious modes can become very difficult and lead to an inaccurate modal identification. This issue mostly concerns TD OMA methods, since FD methods perform much better in structural determination: for instance, FDD techniques can almost eliminate spurious mode problems thanks to a statistical indicator (Brincker et al., 2000). A step forward has been done in TD methods as well; for example, Mohanty and Rixen, 2004 proposed a modification of the LSCE method to account for harmonic components in the response.

Altogether, all the major issues in OMA have been troubleshot little by little, contributing to the refinement of the relevant modal identification algorithms. Nevertheless, some shortcoming still persists, such as the inaccuracy of modal parameters estimates in FD if the signal PSDs are low in resolution, the difficulty in performing repeated tests with mass changes to get scaled modes in case of large and complex structures, the ill-conditioning of outputs measurements when dealing with broad-banded background noise during testing, or even the limitations in modal parameters identification if the frequency content of ambient forces is quite narrow-banded.

In the light of these considerations, it is clear that issues related to sensing equipment, type of modal analysis technique to adopt, data acquisition system, data processing, and removal of noise and environmental effects must be carefully handled to succeed in the dynamic characterization of structural systems. Furthermore, a thorough test planning tailored to the specificity of the structure to characterize and to the objectives to achieve should always be made beforehand. The applications described in the next section will give a better insight into these aspects when dealing with historical constructions.

\subsection{Applications}

Ambient vibration tests (AVTs) supported by output-only modal identification techniques are definitely the best nondestructive tools available to characterize the dynamic behavior of ancient masonry structures. Although still limited in number, several applications of OMA techniques to historic buildings can be found in literature (e.g., Gentile and Saisi, 2007; Ramos et al., 2010a, 2010b; Saisi and 
Gentile, 2015; Ubertini et al., 2016; Masciotta et al., 2016, 2017). Hereafter, three case study applications on full-scale monumental structures are presented with the aim of illustrating the main steps involved in the system characterization process of historic masonry structures and highlighting the important role that dynamic identification plays for a complete comprehension of the actual structural behavior of such complex constructions.

\subsubsection{Mogadouro Clock Tower}

Located within the castle perimeter of the homonymous town in the Northeast of Portugal, the Mogadouro Clock Tower is a historic masonry structure built after 1559 to serve the nearby church as a bell tower (Fig. 8.3). The fabric is $20.4 \mathrm{~m}$ high and features a rectangular cross-section of $4.7 \times 4.5 \mathrm{~m}^{2}$ with masonry walls of about $1 \mathrm{~m}$ thickness. Large granite stones are used at the corners, whereas the central part of the walls mainly consists of rubble stones with thick lime mortar joints. At the top level, eight masonry columns support the roof body.

Due to the lack of maintenance, the tower appeared in very poor condition, showing out-of-plane displacements, large cracks, material deterioration, and biologic growth throughout. The parts mainly affected were the east and west façades, where deep cracks were splitting the box cross-section of the tower into two separate $\mathrm{U}$ bodies, thereby compromising the structural integrity (Fig. 8.4). Conservation works were carried out to reinstate the tower safety, including lime grout injections for the consolidation of the walls, replacement of material with high level of degradation, filling of voids and losses, and installation of tie-rods at two levels.

To evaluate the global response of the tower before and after the works, AVTs were conducted making use of wind and traffic as excitation sources (Ramos et al., $2010 \mathrm{a}, \mathrm{b})$. The response of the tower was acquired in 54 selected points by means of uniaxial piezoelectric accelerometers, deployed according to the layout shown in

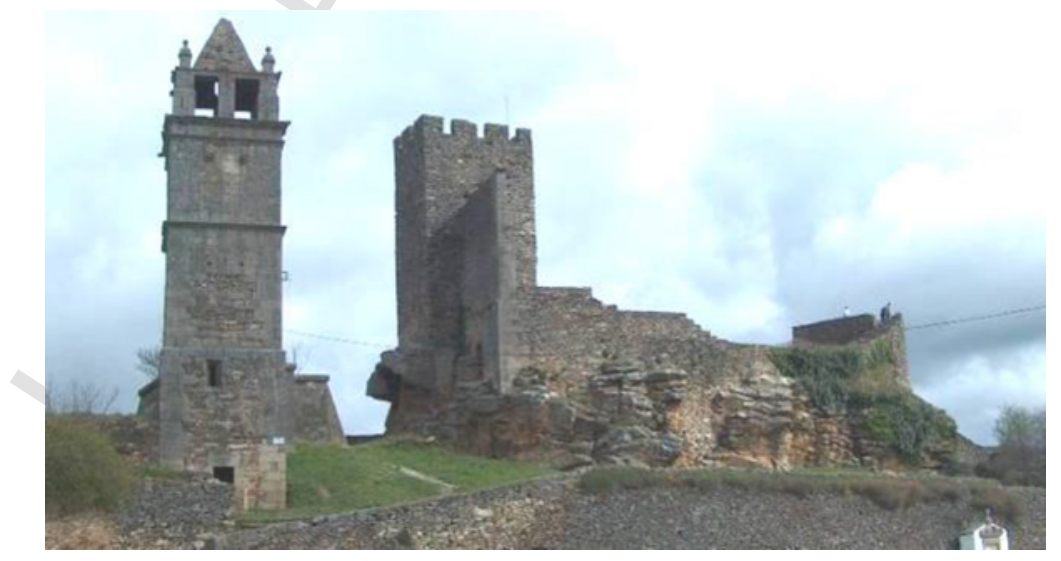

Figure 8.3 The clock tower and the Mogadouro castle. 


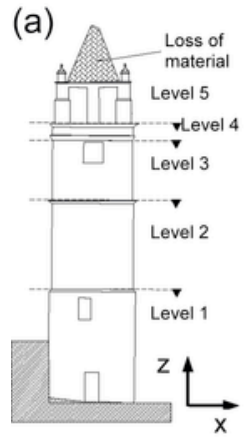

(e)

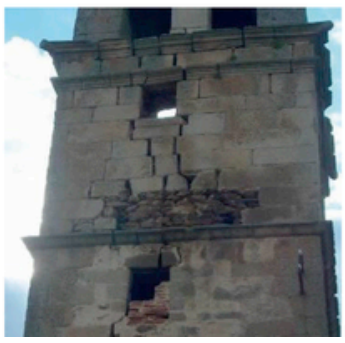

(b)

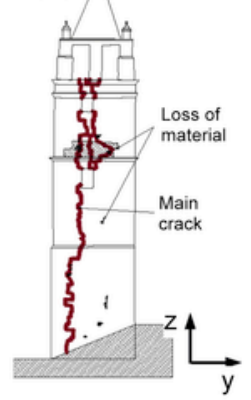

(f)

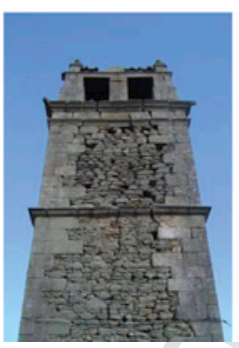

(c)

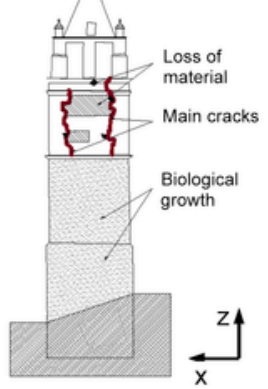

(g)

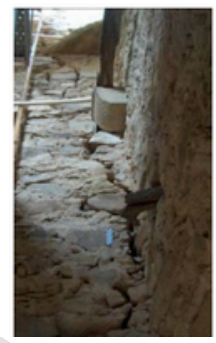

(d)

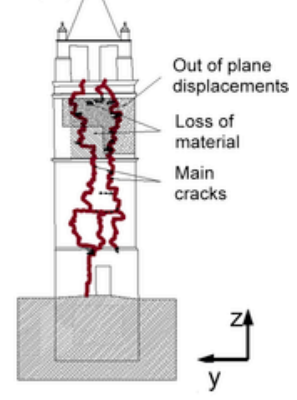

(h)

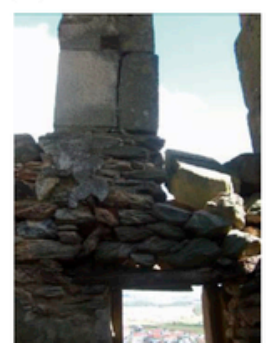

Figure 8.4 Damage survey in the tower: (a) south, (b) east, (c) north, and (d) west façades; cracks on the (e) east and (f) west fronts; (g) inner crack in the west façade; and (h) example of material loss.

Fig. 8.5. Based on the results of a preliminary FE dynamic analysis, the nodal processes were recorded with a sampling frequency of $256 \mathrm{~Hz}$ for a duration of about $11 \mathrm{~min}$ to ensure an acquisition time window 2000 times larger than the

(a)

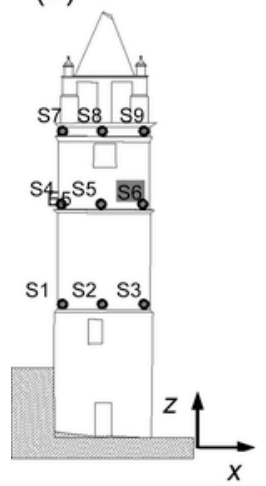

(b)

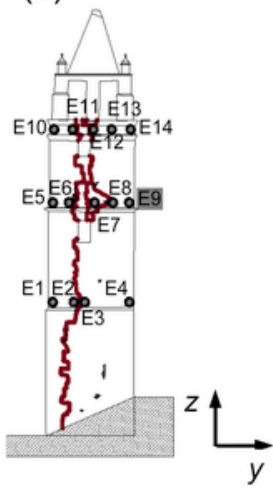

(c)

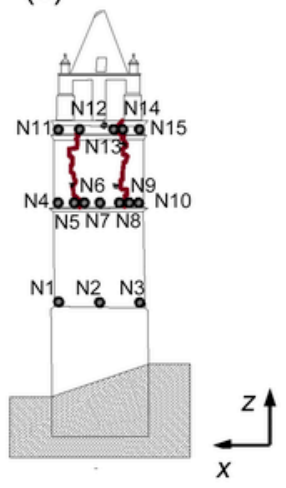

(d)

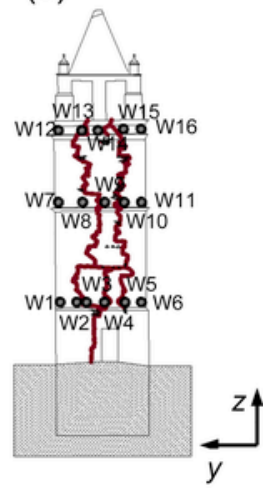

Figure 8.5 Sensor layout adopted in the AVTs of the Mogadouro tower: (a) south, (b) east, (c) north, and (d) west façades (reference sensors are indicated inside a grey box). 
fundamental period of the structure. The same test planning and measurement points were adopted before and after the works.

For either structural condition, the dynamic parameters were estimated by comparing the results from two well-known and complementary OMA techniques: the EFDD (Brincker et al., 2001) and the SSI (Peeters and De Roeck, 1999) methods, implemented in the commercial software ARTeMIS (SVS, 2006). The application of both techniques allowed the identification of seven vibration modes in the frequency ranges $2-9 \mathrm{~Hz}$ and $2-17 \mathrm{~Hz}$ for the damaged and undamaged conditions, respectively. The estimated natural frequencies and damping ratios are summarized in Table 8.1, whereas the corresponding mode shapes and modal assurance criterion (MAC) values are displayed in Fig. 8.6. For the sake of brevity, only the modal features identified by the SSI are shown.

The global parameter results relevant to the two structural conditions reveal an average increase of $50 \%$ in terms of frequency values, while damping decreases around $40 \%$. Concerning the experimental mode shapes, similar configurations are observed for the first five vibration modes, distinguishing four dominant bending modes in the two main planes of the tower (modes 1,2, 4, and 5) and one torsional mode (mode 3), whereas modes 6 and 7 appear swapped. However, despite the apparent resemblance, the MAC, i.e., a statistical indicator of the degree of similarity between two mode shape vectors, denotes a weak correlation between comparable mode shapes, reading values lower than 0.65 . This result is clearly due to the local protuberances affecting the mode shape configurations of the damaged tower both in the upper part and in the areas close to the cracks because of the presence of local damage mechanisms before the works. On the contrary, a monolithic behavior characterizes the global response of the tower after the conservation works.

The analysis of the results allows one to conclude that the presence of damage changed significantly the dynamic behavior of the tower with respect to the possible original configuration, but the structural intervention enabled the reduction of the nonlinear phenomena effects, leading to a stiffer system. Hence, the strengthening works were considered efficient.

Finally, a 3D numeric model was built, and an FE model updating analysis was performed to better assess the dynamic response of the tower before and after the retrofitting (Ramos, 2007). The numeric models simulating the two structural conditions were tuned by exploiting the experimental modal features extracted through AVTs to find the unknown structural parameters and obtain a quantitative indication of the damage extent. Since modal data, namely frequencies and mode shapes, are nonlinear functions of the uncertain model properties, a nonlinear weighted least squares problem was used for the tuning and solved with an iterative sensitivity-based optimization method. The objective function to be minimized was composed by the residuals between experimental and numeric frequencies, as well as between experimental and numeric mode shapes. Taking into account the possible differences between material properties, the Young's modulus of the different parts was selected as the physical parameter to be updated, given its strong influence on the modal data and its high sensitivity to damage. Fig. 8.7(a) illustrates the final 3D 
Table 8.1 Dynamic response of Mogadouro Tower before and after consolidation works

\begin{tabular}{|c|c|c|c|c|c|c|c|c|c|c|}
\hline Mode & Before & & After & & $\Delta_{f}(\%)$ & Before & & After & & $\Delta_{\xi}(\%)$ \\
\hline & $f(\mathrm{~Hz})$ & $\mathrm{CV}_{f}(\%)$ & $f(\mathbf{H z})$ & $\mathrm{CV}_{f}(\%)$ & & $\xi(\%)$ & $\mathrm{CV}_{\xi}(\%)$ & $\xi(\%)$ & $\mathrm{CV}_{\xi}(\%)$ & \\
\hline $1 \mathrm{st}$ & 2.15 & 1.85 & 2.56 & 0.21 & +19.28 & 2.68 & 219.51 & 1.25 & 0.13 & -53.26 \\
\hline 2nd & 2.58 & 1.05 & 2.76 & 0.30 & +6.70 & 1.71 & 94.02 & 1.35 & 0.17 & -21.00 \\
\hline $3 r d$ & 4.98 & 0.69 & 7.15 & 0.27 & +43.67 & 2.05 & 65.33 & 1.20 & 0.14 & -41.32 \\
\hline 4 th & 5.74 & 1.56 & 8.86 & 0.47 & +54.37 & 2.40 & 24.27 & 1.31 & 0.13 & -45.72 \\
\hline 5 th & 6.76 & 1.13 & 9.21 & 0.21 & +36.13 & 2.14 & 31.74 & 1.16 & 0.12 & -45.65 \\
\hline 6 th & 7.69 & 2.94 & 15.21 & 2.24 & +97.87 & 2.33 & 55.98 & 2.54 & 0.24 & +9.11 \\
\hline 7 th & 8.98 & 1.21 & 16.91 & 1.40 & +88.27 & 2.30 & 46.39 & 1.49 & 0.23 & -35.07 \\
\hline Avg & - & 1.49 & - & 0.73 & +49.47 & 2.23 & 76.75 & 1.47 & 0.17 & -40.34 \\
\hline
\end{tabular}

*Average value of damping calculated only for negative differences. 


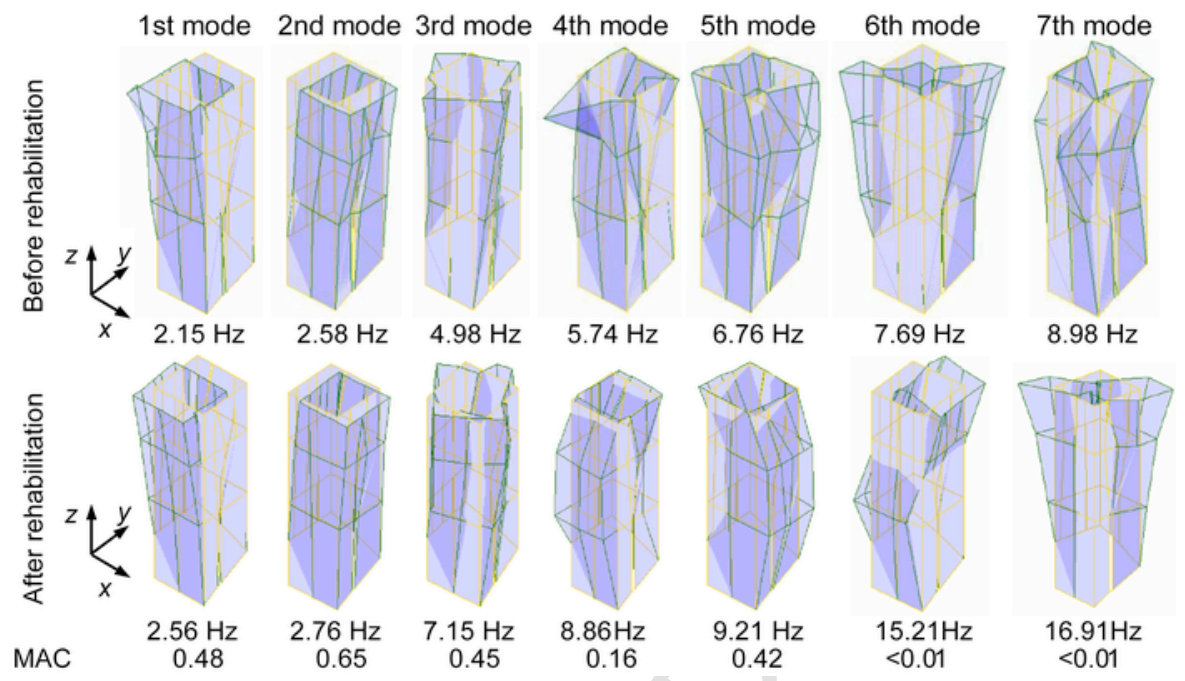

Figure 8.6 Experimental mode shapes and MAC values before and after rehabilitation works.
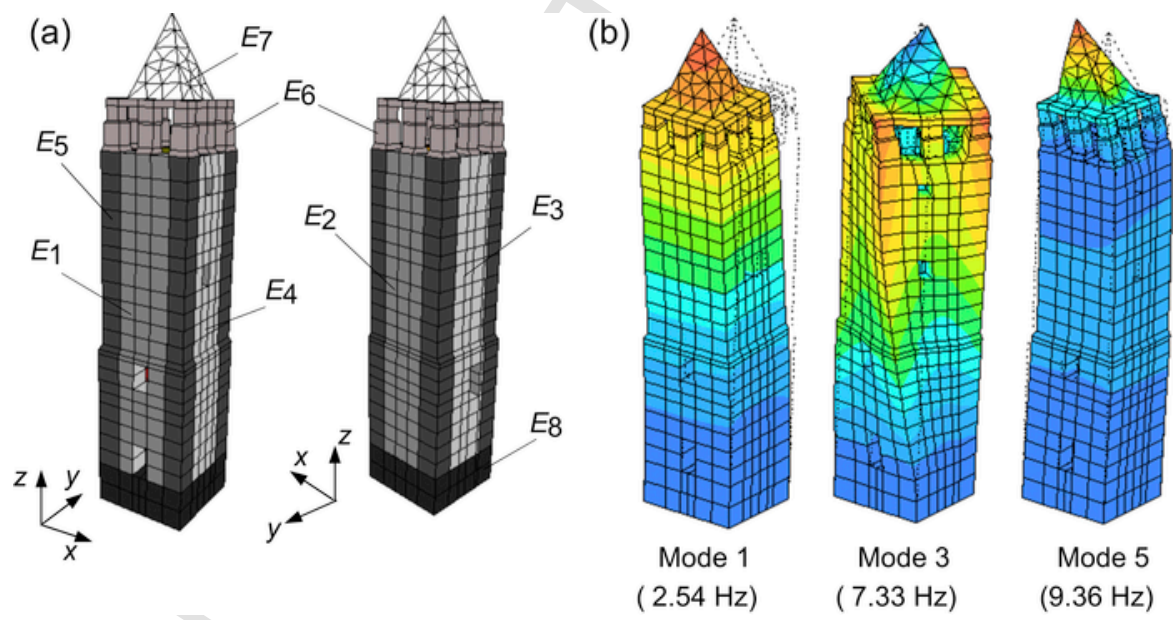

Figure 8.7 FEMU of the tower: (a) 3D model with updating parameters; (b) numeric mode shapes of the consolidated structure.

model where the updating parameters are indicated, and Fig. 8.7(b) shows selected tuned modes of the consolidated tower, which present very good agreement with the experimental counterparts. The values of the eight updating parameters obtained from the FEMU of both structural conditions are presented in Table 8.2. The comparison of the results reveals a threefold increase of the Young's modulus in the south, east and west façades of the tower as well as in the upper part, meaning that 
Table 8.2 Comparison between FEMU parameters before and after consolidation works

\begin{tabular}{|lllll|}
\hline $\begin{array}{l}\text { Updating } \\
\text { parameters }(\mathbf{G P a})\end{array}$ & $\begin{array}{l}\text { Before works } \\
(\mathbf{G P a})\end{array}$ & $\begin{array}{l}\text { After works } \\
\mathbf{( G P a )}\end{array}$ & $\begin{array}{l}\text { Difference } \\
\mathbf{( G P a )}\end{array}$ & $\begin{array}{l}\text { Relative } \\
\text { values }\end{array}$ \\
\hline$E_{1}$ (south) & 0.687 & 1.974 & +1.287 & 2.87 \\
$E_{2}$ (north) & 2.210 & 2.210 & - & 1.00 \\
$E_{3}$ (west) & 0.302 & 1.075 & +0.773 & 3.56 \\
$E_{4}$ (east) & 0.276 & 0.804 & +0.528 & 2.91 \\
$E_{5}$ (corners) & 3.870 & 3.875 & +0.005 & 1.00 \\
$E_{6}$ & 0.380 & 1.210 & +0.830 & 3.18 \\
$E_{7}$ (roof) & 0.083 & 0.195 & +0.112 & 2.35 \\
$E_{8}$ (foundation) & 5.997 & 5.997 & - & 1.00 \\
\hline \hline
\end{tabular}

the structural damage in these areas was much more severe than in the north wall or at the corners, and that the strengthening works effectively reestablished the tower safety.

\subsubsection{Qutb Minar tower}

Built to glorify the victory of Islam against idolatry, the Qutb Minar is one of the tallest stone masonry towers in the world, featuring a height of about $73 \mathrm{~m}$ (Fig. 8.8). The construction of the monument began around 1202 during the reign of Qutab-ud-din Aibak, but the erection stopped at the first story. A further three stories were added by Aibak's successor, Iltutmish. In 1369 the topmost story was damaged by lightning and later rebuilt by Firoz Shah Tughlaq, who also added another story. Following the earthquake of 1503, repairs and restauration works were carried out by Sikandar Lodi. The inscriptions and ornamentations patterned on the different sections of the Minar fluted body reveal the history of its construction.

A world heritage monument since 1993, the Qutb Minar tower consists of five superimposed stories and a polylobed circular cross-section tapering upward from 14.07 to $3.13 \mathrm{~m}$, placed over a $1.7-\mathrm{m}$-high square pedestal, which in turn overlies a 7.6-m-high square rubble masonry layer. The tower is composed by a three-leaf exterior masonry shell and a central masonry shaft (Fig. 8.9(a)), connected to each other by a stone "bracing" system (Fig. 8.9(b)) and a helical staircase with 379 steps going up to the top. Small and large openings pierce the exterior masonry shell at different levels, ensuring diffuse ventilation inside the tower (Fig. 8.9(c)).

The dynamic response of the structure to ambient vibrations was measured by means of uniaxial piezoelectric accelerometers in 20 points distributed over five 


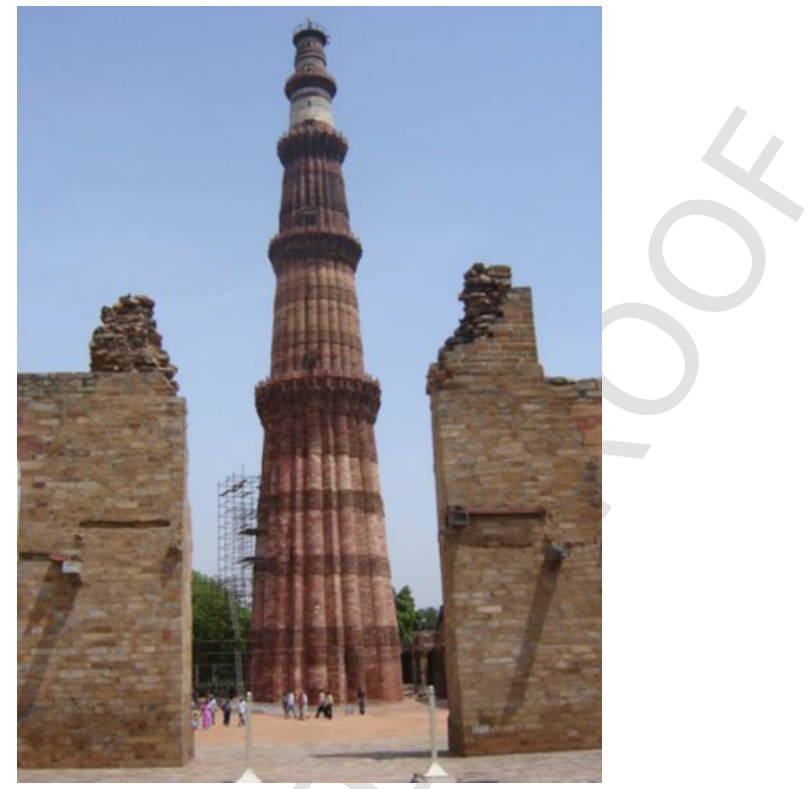

Figure 8.8 The Qutb Minar tower.

levels, resulting into four aligned points per level, of which two with sensors in the three directions $(x, y$, and $z$ ) and two with sensors in the $y$ direction only (Fig. 8.10). Such a test layout was chosen to evaluate the degree of connection between external shell and central core, since the two structural parts could have manifested a different dynamic response (Ramos et al., 2006). Preliminary numeric analyses assisted in the selection of the best sensor location as well as in the definition of the acquisition parameters. Thus, the nodal response processes of all 20 selected points were recorded through nine sequential setups, with a sampling frequency of $100 \mathrm{~Hz}$ and for a total duration of $20 \mathrm{~min}$, approximately 1000 times the minimum expected period.

Two different output-only modal identification techniques were used to estimate the dynamic parameters of the minaret, viz. frequencies, mode shapes, and damping ratios. Both techniques operate in the TD and are based on the SSI method (Peeters and De Roeck, 1999): the SSI-UPC (unweight principal component) and the SSI-PC (principal component). In both SSI-driven implementations, pairs of closely spaced frequencies were identified, especially regarding the first two modes. This result depends on to the axisymmetric cross-section of the tower, a fact that generally leads to near pairs of bending mode shapes. This explains the recourse to TD techniques for the modal identification, as the estimation of closely spaced modes with FD methods is notoriously difficult.

The application of SSI techniques to AV data allowed the identification of 14 vibration modes in the frequency range $0.70-9 \mathrm{~Hz}$ : 10 dominant bending modes, two torsional modes, one axial mode, and one undefined mode. Table 8.3 summarizes the 


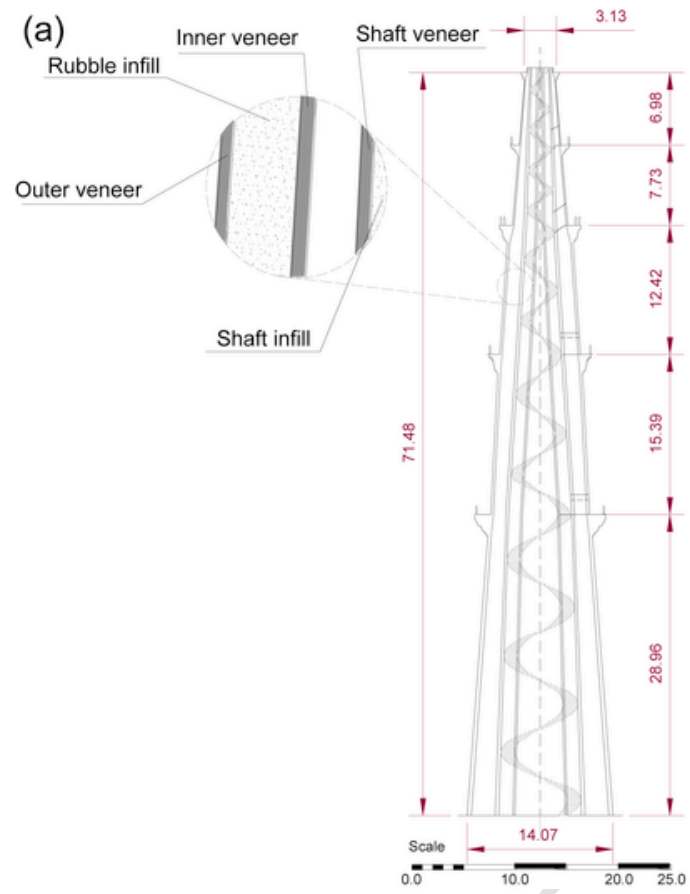

(b)

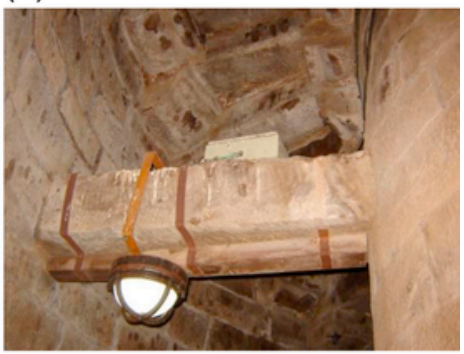

(c)

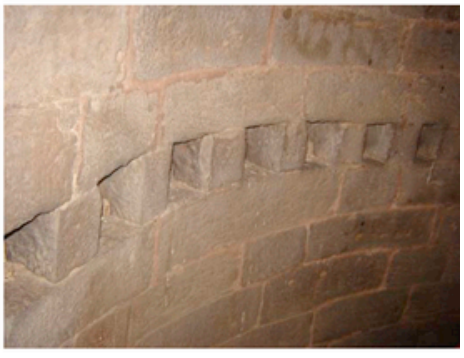

Figure 8.9 Geometric survey of the tower: (a) composition of the exterior masonry shell; (b) bracing system between exterior shell and central shaft; and (c) detail of the openings.

experimental results. Very low percentage errors in terms of frequency values are found comparing the two identification procedures, and quite a good correlation (MAC > 0.70) exists between all comparable modes, except for modes 2 and 7.

Fig. 8.11 shows a perspective view of the identified vibration modes, whereas Fig. 8.12 reports the top view of the 10 estimated bending modes. As it can be observed, the directions of each pair of closely spaced modes are almost perpendicular, owing to the asymmetry of the tower cross-section.

Since the definition of the first two mode shapes in the upper part of the tower were not very clear (the central shaft seemed to present higher displacement compared to the exterior shell), an additional dynamic identification was performed aiming at improving the results. In this further analysis the records acquired at the fourth level were removed from the data processing since they seemed to worsen the modal estimation. Notwithstanding, this second identification process provided very similar results, allowing to assert the accuracy of the first dynamic identification and to impute the unclear definition of the first two bending modes in the upper levels to a decreased degree of connection between the top parts of exterior shell and central shaft. The experimental modal features so identified were ultimately exploited for the validation of the preliminary numeric model that was later used for the seismic assessment of the Qutb Minar (Peña et al., 2008). 


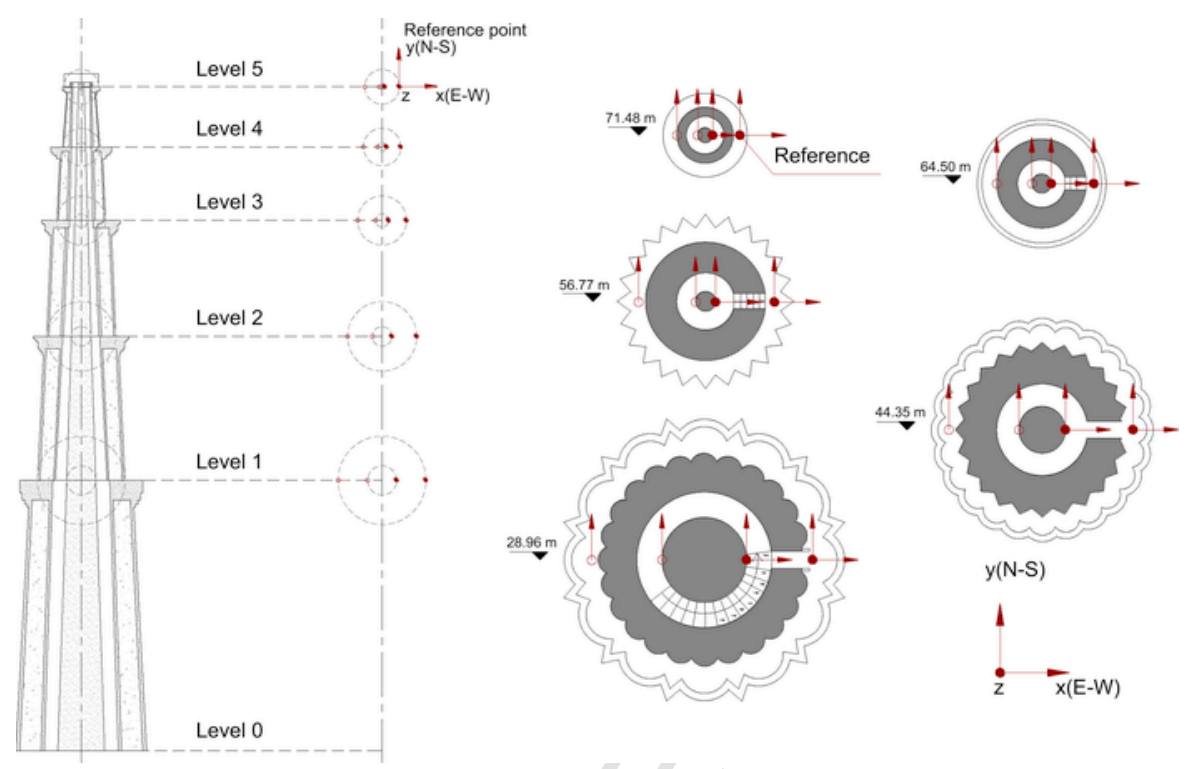

Figure 8.10 Sensor layout adopted in the AVTs of the Qutb Minar tower.

\subsubsection{Saint Torcato church}

Saint Torcato church is a neo-Manueline style historic building located in the homonymous village, North of Portugal. The church is characterized by a Latin cross-longitudinal plan with a central nave of nearly $58 \mathrm{~m}$ length and $11 \mathrm{~m}$ width ending into an apse. A transept of about $37 \mathrm{~m}$ length and $11.5 \mathrm{~m}$ width intersects the nave at two-thirds of its development (Fig. 8.13). Either limb is covered with a barrel vault, while the crossing between longitudinal nave and transept is capped with a dome laying on an octagonal tambour. A roof consisting of wooden trusses protects the vaults beneath. Two spired towers with a rectangular plan of $7.5 \times 6.3 \mathrm{~m}$ and a total height of $58 \mathrm{~m}$ symmetrically frame the façade. Either tower has an inner stone staircase running along the walls up to the level of the bells, present only in the western tower.

The construction of the church started in 1825 and stretched over nearly two centuries, involving several building phases. Hence, different materials can be distinguished in the fabric. Towers and nave are made of three-leaf walls consisting of outer regular granite masonry blocks with thin mortar joints and inner rubble core, whereas apse and main altar are built by reinforced concrete walls covered with granite veneer. The thickness of the walls ranges from $1.1 \mathrm{~m}$ of the apse to $1.3 \mathrm{~m}$ of the nave and $1.4 \mathrm{~m}$ of the towers, while the thickness of the façade tapers upward, varying from 2.3 to $1.4 \mathrm{~m}$.

The church exhibited moderate to severe structural damage. The most affected part was the façade where a V-cracking pattern arising from the keystone of the 
Table 8.3 Experimental results of the global dynamic parameters identified from AVTs

\begin{tabular}{|lllllll|}
\hline Mode & & UPC & PC & Error (\%) & MAC & $\boldsymbol{\xi}(\%)$ \\
\hline & & $\boldsymbol{f}(\mathbf{H z})$ & $\boldsymbol{f}(\mathbf{H z})$ & & & \\
\hline 1st & Bending & 0.793 & 0.785 & 1.003 & 0.777 & 3.253 \\
3rd & Bending & 0.814 & 0.814 & 0.025 & 0.443 & 2.555 \\
4th & Bending & 1.955 & 1.953 & 0.079 & 0.988 & 1.126 \\
5th & Bending & 3.741 & 3.741 & 0.001 & 0.994 & 0.749 \\
6th & Bending & 3.861 & 3.864 & 0.061 & 0.992 & 1.394 \\
7th & Torsion & 4.400 & 4.484 & 1.889 & 0.309 & 3.570 \\
8th & Bending & 6.006 & 5.966 & 0.671 & 0.743 & 1.653 \\
9th & Bending & 6.146 & 6.073 & 1.186 & 0.832 & 1.347 \\
10th & Axial & 6.282 & 6.261 & 0.330 & 0.907 & 1.270 \\
11th & Torsion & 6.977 & 6.968 & 0.137 & 0.865 & 0.972 \\
12th & Undefined & 8.090 & 8.174 & 1.033 & 0.690 & 2.131 \\
13th & Bending & 8.525 & 8.530 & 0.065 & 0.788 & 2.247 \\
14th & Bending & 8.669 & 8.663 & 0.064 & 0.879 & 2.471 \\
\hline \hline
\end{tabular}

portal was observed. The major of the two cracks split the façade into two macro-blocks, being as deep as the thickness of the wall and reaching over $50 \mathrm{~mm}$ width at the tympanum level (Fig. 8.14). The first monitoring results reported an increasing crack opening rate of $0.1 \mathrm{~mm} /$ year, pointing to the façade as the most active part of the church. Besides the cracking pattern, both towers were leaning toward west direction but with different inclination ratios. The continuity of the façade cracks inside the church and the separation movements of the towers indicated a settlement of the front part of the structure due to higher stresses at the base associated with the weight of towers, as well as possible soil problems. The outcome of the geotechnical survey confirmed this hypothesis, revealing a soil profile heterogeneous and variable along the church longitudinal section, with the identification of a landfill right in front of the main façade.

To better understand and characterize the global behavior of the church, an extensive campaign of OMA tests was carried out (Ramos et al., 2013). The dynamic response of the structure was measured in 35 points by means of high-sensitivity uniaxial piezoelectric accelerometers deployed as schematized in Fig. 8.15. Due to 


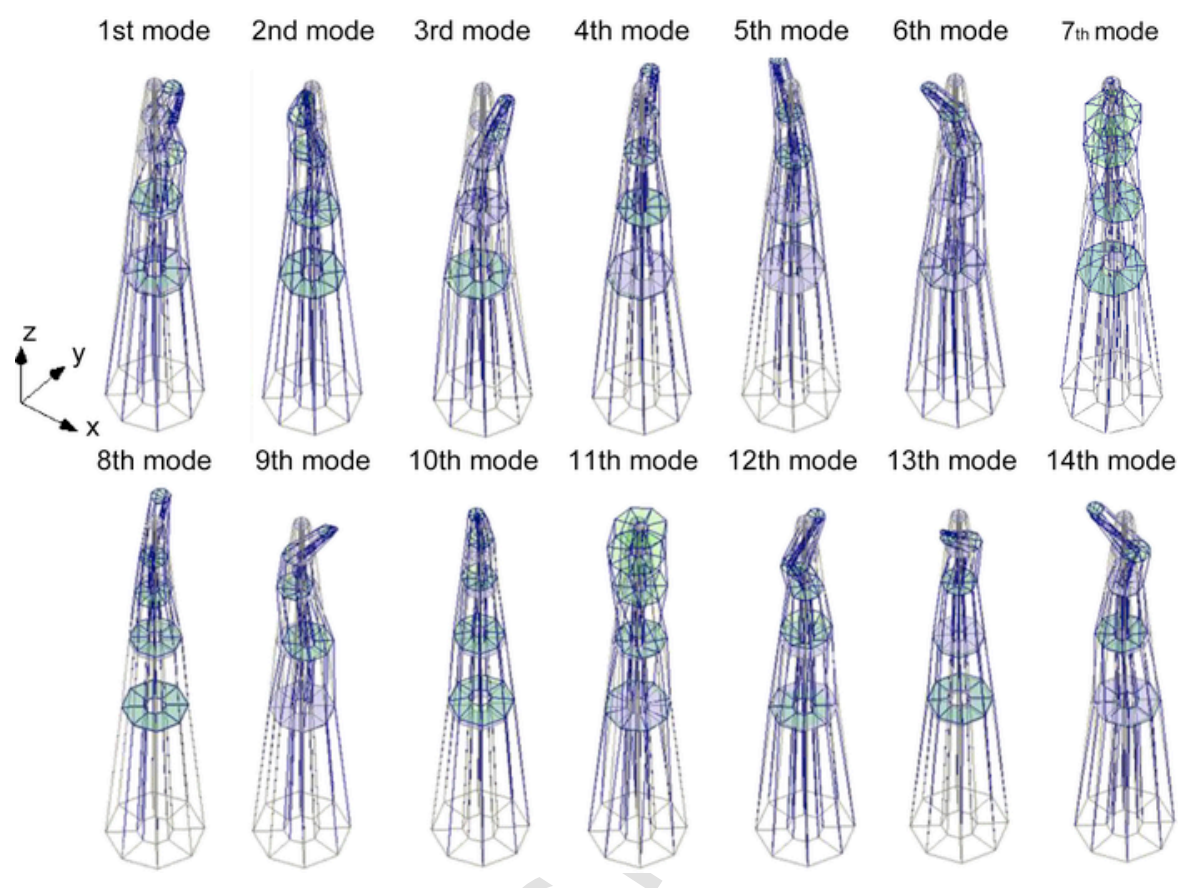

Figure 8.11 Perspective view of the identified vibration modes of the minaret.
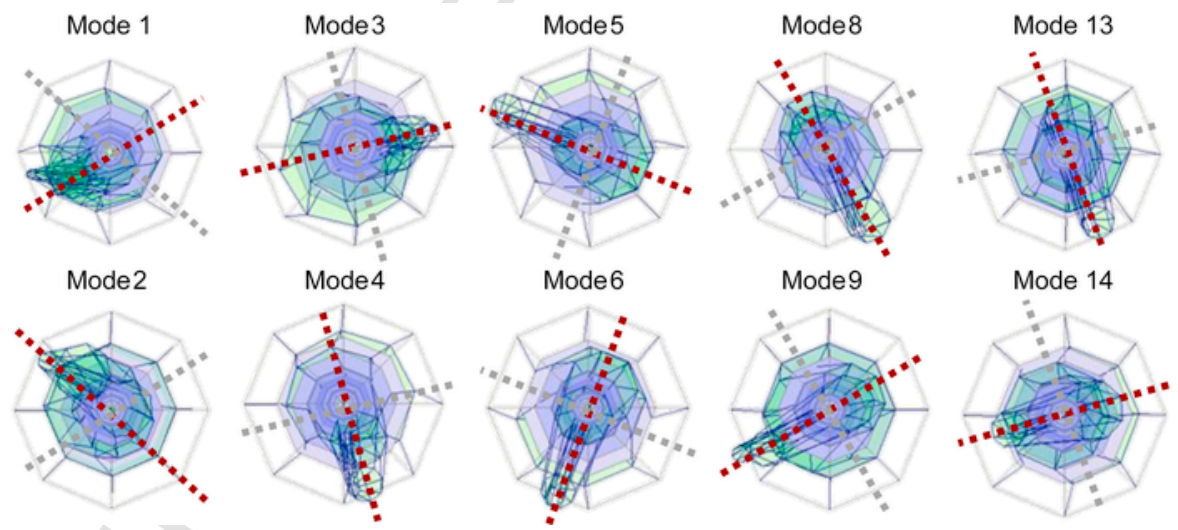

Figure 8.12 Top view of the identified bending modes of the minaret.

the number of accelerometers and the long distance between them, the measurements were taken in nine test setups, keeping four reference points at the top of the towers (two mutually perpendicular accelerometers per tower) due to the high amplitude and significant modal contribution of these points. In each setup, the accelerations were recorded with a sampling rate of $200 \mathrm{~Hz}$ for a total duration of $10 \mathrm{~min}$. 
(a)

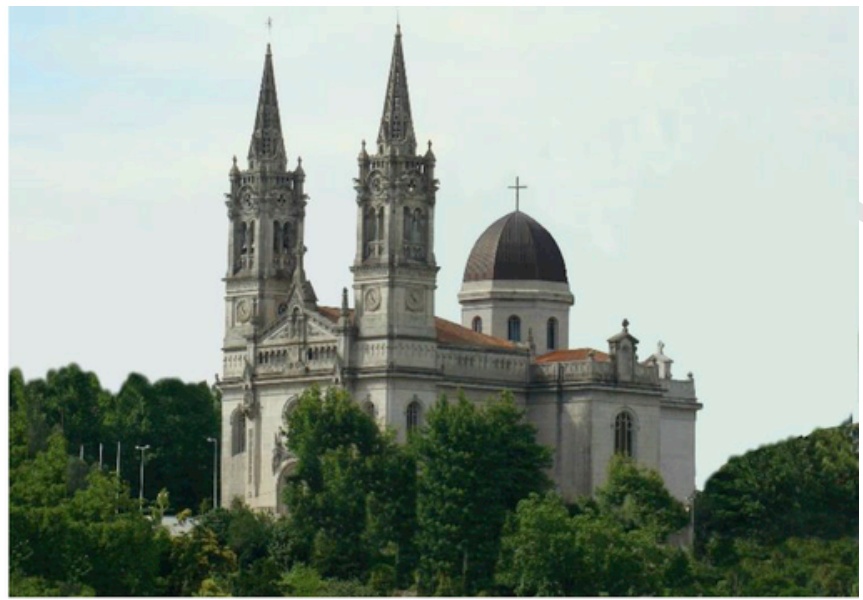

(b)

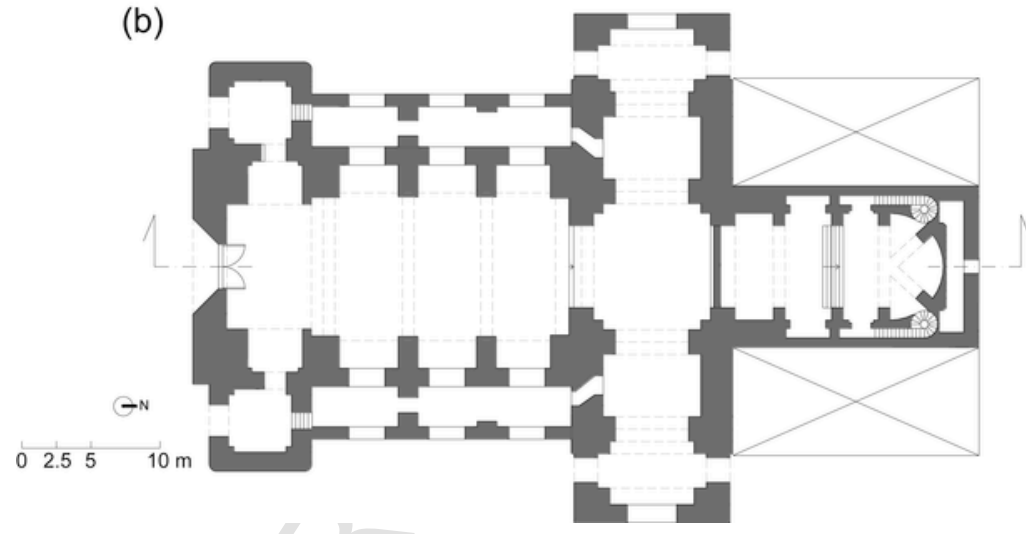

Figure 8.13 Church of Saint Torcato: (a) general view and (b) plan.

The modal properties of the structure were determined using both nonparametric and parametric OMA processing routines, namely the FDD and the EFDD (Brincker et al., 2001), and the crystal clear stochastic subspace identification (CC-SSI) (Peeters and De Roeck, 1999). The OMA results are presented in Table 8.4 and Fig. 8.16.

As it can be seen, only four vibration modes in the frequency range $2-3 \mathrm{~Hz}$ were identified, reading relative errors lower than $1.4 \%$ in terms of natural frequencies and consistent damping values regardless of the processing routines $(1 \%-2 \%$ in all four modes). As for the mode shapes, the first two are associated with in-phase bending modes of the towers in transversal and longitudinal directions, while the third and fourth correspond to out-of-phase bending modes of the towers. One of the main difficulties when performing AVTs tests in historical constructions is that ambient noise might not be strong enough to act as a broadband input signal and 


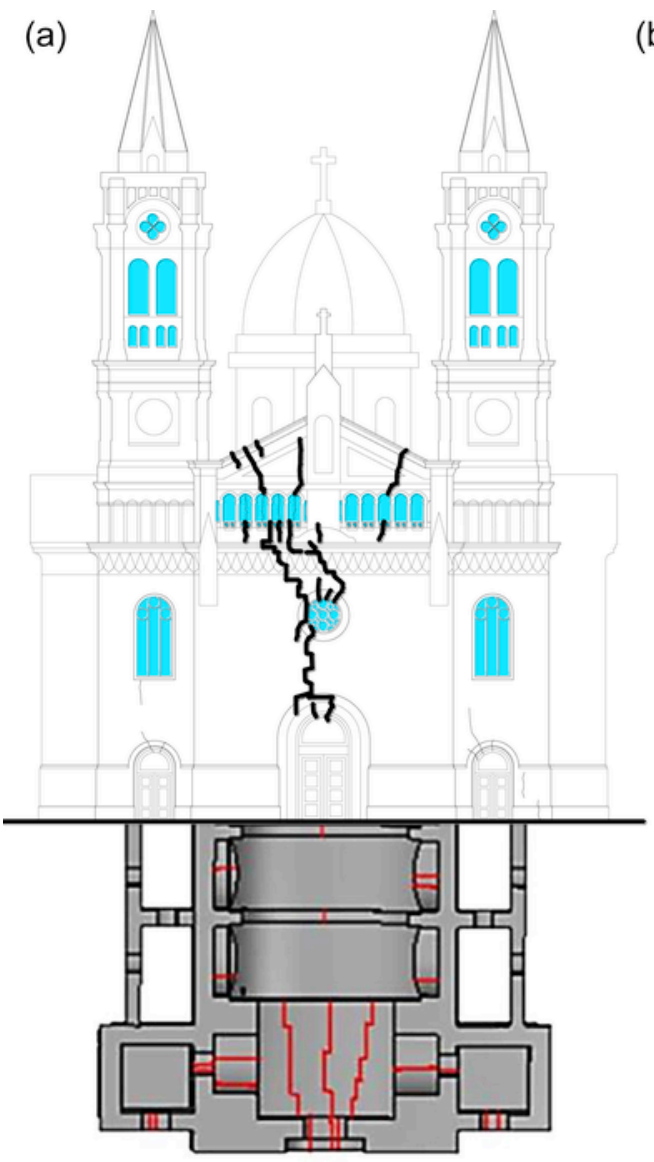

(b)
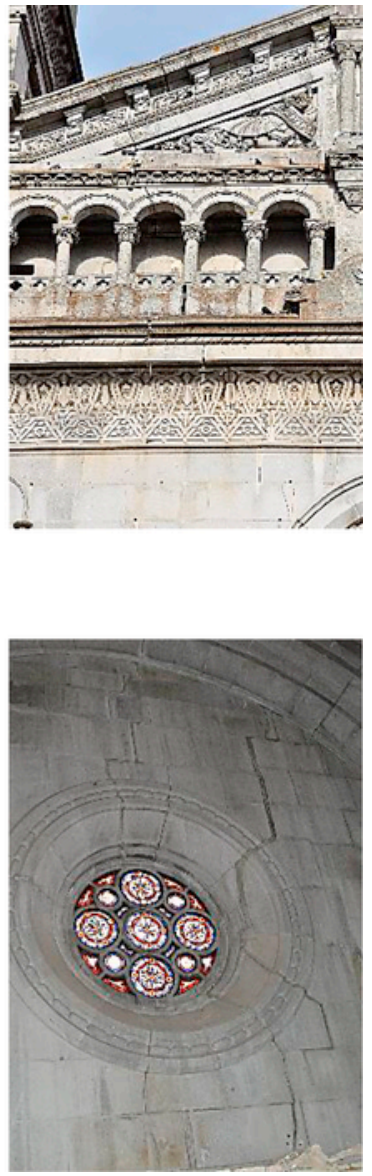

Figure 8.14 Structural damage in the church: (a) crack pattern of the façade and choir vault; and (b) details of the cracks.

excite high-frequency modes. This was the case for the present case study, as the TD results indicated very low levels of excitations $(\mathrm{RMS}=0.037 \mathrm{mg})$. Nevertheless, the most meaningful vibration modes of the church, namely those associated with the tower's movements, could be accurately identified.

The OMA results were further exploited to calibrate a previously built FE model representative of the front part of the church (Lourenço and Ramos, 1999) to perform a more accurate static nonlinear analysis of both nave and façade (including towers), these being the most compromised parts of the structure. The missing part was simulated through interface elements with appropriate stiffness at the intersection with the transept. The same elements were used to simulate the soil structure interaction. As the modal results of numeric models are sensitive to material and physical properties, the following parameters were selected as updating 
(a)

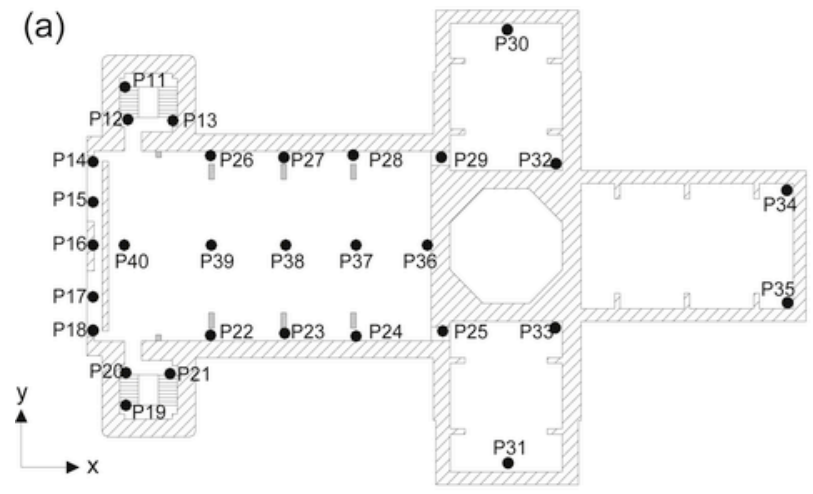

(b)

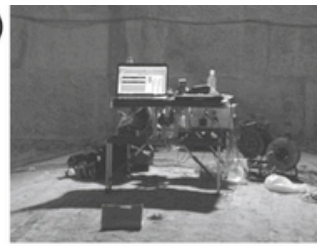

(c)

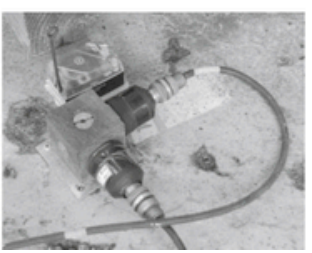

Figure 8.15 OMA test of Saint Torcato church: (a) sensors layout; (b) data acquisition system above the nave; and (c) two node accelerometers.

Table 8.4 Results of the operational modal analysis of Saint Torcato church

\begin{tabular}{|llllll|}
\hline Mode & FDD & EFFD & \multicolumn{3}{c|}{ CC-SSI } \\
\hline & $\boldsymbol{f}(\mathbf{H z})$ & $\boldsymbol{f}(\mathbf{H z})$ & $\boldsymbol{\xi}(\%)$ & $\boldsymbol{f}(\mathbf{H z})$ & $\boldsymbol{\xi}(\%)$ \\
\hline 1st & $2.15(0.5 \%)$ & $2.14(<0.01 \%)$ & $1.8(20 \%)$ & 2.14 & 1.5 \\
2 nd & $2.64(0.4 \%)$ & $2.62(0.4 \%)$ & $1.5(36 \%)$ & 2.63 & 1.1 \\
3 rd & $2.89(1.4 \%)$ & $2.89(1.4 \%)$ & $0.8(43 \%)$ & 2.85 & 1.4 \\
4th & $2.94(1.4 \%)$ & $2.94(0.3 \%)$ & $0.8(47 \%)$ & 2.93 & 1.5 \\
\hline \hline
\end{tabular}

The percentage in parenthesis indicates the relative error, taking as reference the results of the CC-SSI method.
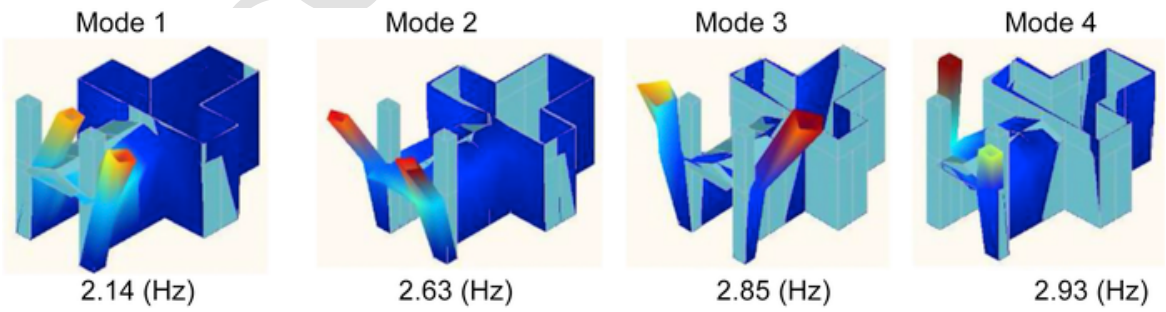

Figure 8.16 Identified experimental mode shapes.

variables: the Young's modulus of the masonry $\left(E_{m}\right)$, the normal stiffness of weak soil at the region of the towers $\left(E_{s}\right)$, and the normal and shear stiffness of the 
interface elements at the missing part of the model $\left(E_{t n}\right)$ and $\left(E_{t s}\right)$. For the updating process, the Douglas-Reid method (Douglas and Reid, 1982) was implemented, considering reasonable lower and upper bounds for the updating variables to avoid unrealistic results. Table 8.5 and Fig. 8.17 present the summary of the updating process and demonstrate its importance for obtaining reliable numeric models able to replicate the actual response of the structures. Indeed, the final values of the updating parameters can differ more than $80 \%$ compared to the initial values adopted in the model.

Table 8.5 Results of the FEMU process

\begin{tabular}{|lllll|}
\hline $\begin{array}{l}\text { Updating } \\
\text { parameters }\end{array}$ & $\begin{array}{l}\text { Initial value } \\
(\mathbf{G P a})\end{array}$ & $\begin{array}{l}\text { Optimized interval of } \\
\text { values (GPa) }\end{array}$ & $\begin{array}{l}\text { Updated value } \\
(\mathbf{G P a})\end{array}$ \\
\hline & & $\begin{array}{l}\text { Lower } \\
\text { bound }\end{array}$ & $\begin{array}{l}\text { Upper } \\
\text { bound }\end{array}$ & \\
\hline$E_{m}$ & 10 & 4 & 15 & 5.64 \\
$E_{s}$ & 3.9 & 0.039 & 3.9 & 0.63 \\
$E_{t n}$ & 0.1 & 0.001 & 0.1 & 0.05 \\
$E_{t s}$ & 100 & 1 & 100 & 21.59 \\
\hline \hline
\end{tabular}

(a)

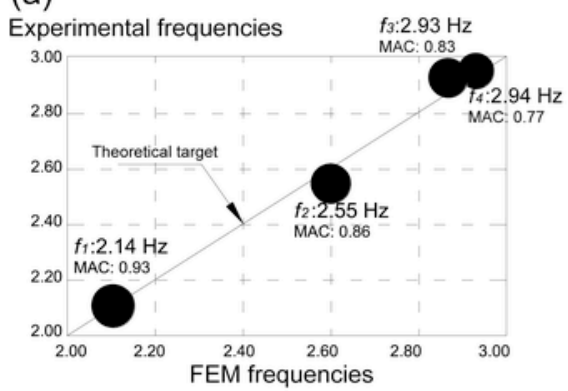

(c)

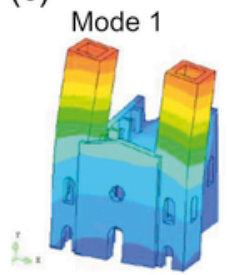

$2.14(\mathrm{~Hz})$

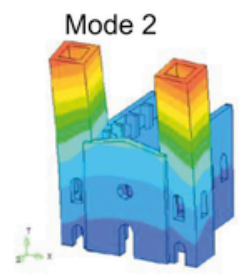

$2.55(\mathrm{~Hz})$ (b)
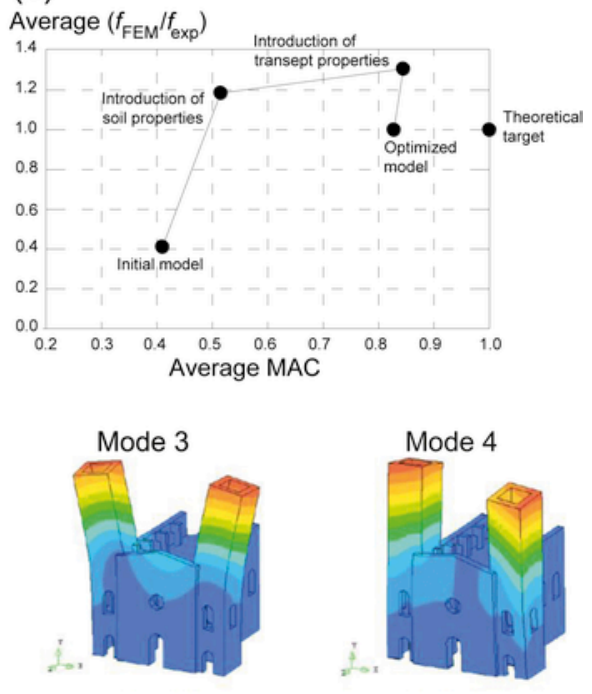

$2.93(\mathrm{~Hz})$

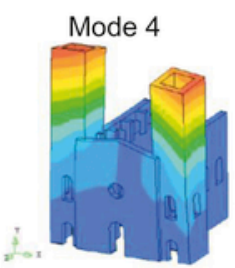

$2.94(\mathrm{~Hz})$

Figure 8.17 Results of the FEMU process. 
In conclusion, the results of the calibrated model showed a very good agreement with the experimental dynamic tests. The updated frequencies are close to the 45-degree theoretical line, which indicates a perfect match between results, and the updated mode shapes are also well-tuned, being that the MAC values are relatively close to the unit in all cases.

\subsection{Conclusions}

Historic masonry structures present peculiar features that make the characterization of their structural behavior not straightforward. Full-scale in situ dynamic testing has proven to be best way to shed light upon the actual performance of these nonconventional systems, being free from many assumptions and simplifications inherently present in reduced-scale laboratory tests and providing the necessary benchmark for the sound calibration of numeric models for advanced structural analyses, damage identification, structural health assessment, validation of consolidation measures, and design of future interventions.

In this chapter, the dynamic identification of three historic masonry structures, namely two towers (Mogadouro in Portugal and Qutb Minar in India) and one church (Saint Torcato in Portugal), is presented and discussed in detail, focusing on both modal testing procedures and data analysis. Dealing with heritage structures, OMA techniques were used in all three cases to fully characterize the dynamic behavior of each system and estimate the relevant modal properties, i.e., frequencies, mode shapes, and damping ratios. The ambient vibration responses of Mogadouro tower and Saint Torcato church have been analyzed using well-known output-only identification techniques both in the frequency and TDs, whereas the vibration response of the Qutb Minar tower has been analyzed only making use of TD techniques, given the difficulty in catching closely spaced modes with FD methods. Notwithstanding the low level of ambient excitation, the main vibration modes of the three structures could be easily identified but for the church's high-frequency modes, likely because of the high stiffness of nave and transept that would have required a stronger broadband excitation source. The work has also shown how experimental dynamic features can be exploited for evaluating the efficiency of structural interventions as well as for modal updating analyses aimed at optimizing FE models for the accurate simulation of the actual response of historic masonry structures.

\section{References}

Aenlle, M.L., Brincker, R., 2013. Modal scaling in operational modal analysis using a finite element model. International Journal of Mechanical Sciences 76, 86-101.

Brincker, R., Andersen, P., Møller, N., 2000. An indicator for separation of structural and harmonic modes in output-only modal testing. In: Proceedings of the 18th International Modal Analysis Conference, Sant'Antonio, TX.

Brincker, R., Zhang, L., Andersen, P., 2001. Modal identification of output-only systems using frequency domain decomposition. Smart Materials and Structures 10, 441-445. 
Brincker, R., Kirkegaard, P., 2001. Special issue on operational modal analysis. Mechanical Systems and Signal Processing 24 (5), 1209-1212.

Brincker, R., Andersen, P., 2003. A way of getting scaled mode shapes in output only modal testing. In: Proceedings of the 21st International Modal Analysis Conference, Orlando, FL.

Cunha, A., Caetano, E., 2006. Experimental modal analysis of civil engineering structures. Journal of Sound and Vibration 40 (6), 12-20.

Douglas, B.M., Reid, W.H., 1982. Dynamic tests and system identification of bridges. Journal of the Structural Division, ASCE 108, 2312, ST10.

Ewins, D.J., 2000. Modal Testing: Theory and Practice. Research Studies Press Ltd., Hertfordshire, UK.

Gentile, C., Saisi, A., 2007. Ambient vibration testing of historic masonry towers for structural identification and damage assessment. Construction and Building Materials 21, 1311-1321.

Lourenço, P.B., Ramos, L.F., 1999. Investigacão sobre as Patologias do Santuário de São Torcato, Final Report 99-DEC/E-5. University of Minho (in Portuguese).

Masciotta, M.G., 2015. Damage Identification of Structures Based on Spectral Output Signals (Ph.D thesis). University of Minho, Guimarães, Portugal-University "G.d'Annunzio" of Chieti-Pescara, Italy.

Masciotta, M.G., Roque, J.C.A., Ramos, L.F., Lourenço, P.B., 2016. A multidisciplinary approach to assess the health state of heritage structures: the case study of the Church of Monastery of Jerónimos in Lisbon. Construction and Building Materials 116, 169-187.

Masciotta, M.G., Ramos, L.F., Lourenço, P.B., Vasta, M., 2017a. Damage identification and seismic vulnerability assessment of a historic masonry chimney. Annals of Geophysics 60 (4), S0442, 1-19.

Masciotta, M.G., Ramos, L.F., Lourenço, P.B., 2017b. The importance of structural monitoring as a diagnosis and control tool in the restoration process of heritage structures: a case-study in Portugal. Journal of Cultural Heritage 27, 36-47.

Maia, N., Silva, J., 1997. Theoretical and Experimental Modal Analysis. Research Studies Press, UK.

Mohanty, P., Rixen, D.J., 2004. Operational modal analysis in the presence of harmonic excitation. Journal of Sound and Vibration 270 (1-2), 93-109.

Parloo, E., Verboven, P., Guillaume, P., Van Overmeire, M., 2001. Sensitivity-based operational mode shape normalisation. Mechanical Systems and Signal Processing 16 (5), $757-767$.

Peeters, B., De Roeck, G., 1999. Reference-based stochastic subspace identification for output-only modal analysis. Mechanical Systems and Signal Processing 13, 855-878.

Peeters, B., De Roeck, G., 2001. Stochastic system identification for operational modal analysis: a review. Journal of Dynamic Systems, Measurement, and Control 123 (4), 659-667.

Peña, F., Lourenço, P.B., Mendes, N., 2008. Seismic assessment of the Qutb minar in Delhi, India. In: Proceedings of the 14th World Conference on Earthquake Engineering, Beijing, China.

Ramos, L.F., Casarin, F., Algeri, C., Lourenço, P.B., Modena, C., 2006. Investigation techniques carried out on the Qutb Minar, New Delhi, India. In: Proceedings of the 5th International Conference on Structural Analysis of Historical Constructions, New Delhi, India.

Ramos, L.F., 2007. Damage Identification on Masonry Structures Based on Vibration Signatures ( $\mathrm{PhD}$ thesis). University of Minho, Portugal. 
Ramos, L.F., De Roeck, G., Lourenço, P.B., Campos-Costa, A., 2010a. Damage identification on arched masonry structures using ambient and random impact vibrations. Engineering Structures 32, 146-162.

Ramos, L.F., Marques, L., Lourenço, P.B., De Roeck, G., Campos-Costa, A., Roque, J.C.A., 2010b. Monitoring historical masonry structures with operational modal analysis: two case studies. Mechanical Systems and Signal Processing 24, 1291-1305.

Ramos, L.F., Aguilar, R., Lourenço, P.B., Moreira, S., 2013. Dynamic structural health monitoring of Saint Torcato church. Mechanical Systems and Signal Processing 35 (1-2), $1-15$.

Reynders, E., 2012. System identification methods for (operational) modal analysis: review and comparison. Archives of Computational Methods in Engineering 19 (1), 51-124, Springer Netherlands, ISSN 1134-3060.

Saisi, A., Gentile, C., 2015. Post-earthquake diagnostic investigation of a historic masonry tower. Journal of Cultural Heritage 16 (4), 602-609.

SVS, 2006. ARTeMIS Extractor Pro User's Manual, Release 3.5. Structural Vibration Solutions, Aalborg, Denmark.

Ubertini, F., Comanducci, G., Cavalagli, N., 2016. Vibration-based structural health monitoring of a historic bell-tower using output-only measurements and multivariate statistical analysis. Structural Health Monitoring 15 (4), 438-457.

Zhang, L., Brincker, R., Andersen, P., 2005. An overview of operational modal analysis: major development and issues. In: Proceedings of the 1st International Operational Modal Analysis Conference. IOMAC 2005, Copenhagen, Denmark. 